\begin{tabular}{|c|l|}
\hline Title & $\begin{array}{l}\text { Unique Epstein-Barr virus (EBV) Iatent gene expression, EBNA promoter usage and EBNA promoter methylation } \\
\text { status in chronic active EBV infection. }\end{array}$ \\
\hline Author(s) & Yoshioka, Mikio; Kikuta, Hideaki; Ishiguro, Nobuhisa; Ma, X iaoming; Kobay ashi, Kunihiko \\
\hline Citation & $\begin{array}{l}\text { Journal of General Virology, 84(5), 1133-1140 } \\
\text { https://doi.org/10.1099/1r.0.18777-0 }\end{array}$ \\
\hline Issue Date & $2003-05$ \\
\hline Doc URL & http://hdl.handle.net/2115/14700 \\
\hline Type & article \\
\hline File Information & JGV 200384(1133).pdf \\
\hline
\end{tabular}

Instructions for use 


\section{Unique Epstein-Barr virus (EBV) latent gene expression, EBNA promoter usage and EBNA promoter methylation status in chronic active EBV infection}

Correspondence

Hideaki Kikuta

hide-ki@med.hokudai.ac.jp

Received 13 August 2002

Accepted 10 January 2003

\author{
Mikio Yoshioka, Hideaki Kikuta, Nobuhisa Ishiguro, Xiaoming Ma \\ and Kunihiko Kobayashi \\ Department of Pediatrics, Hokkaido University School of Medicine, N-15, W-7, Kita-ku, \\ Sapporo 060-8638, Japan
}

\begin{abstract}
Chronic active Epstein-Barr virus infection (CAEBV) has been considered to be a non-neoplastic T-cell lymphoproliferative disease associated with Epstein-Barr virus (EBV) infection. In EBVassociated diseases, the cell phenotype-dependent differences in EBV latent gene expression may reflect the strategy of the virus in relation to latent infection. We previously reported that EBV latent gene expression was restricted; EBV nuclear antigen 1 (EBNA1) transcripts were consistently detected in all spleen samples from five CAEBV patients, but EBNA2 transcripts were detected in only one sample. EBV latent gene expression is controlled by distinct usage of three EBNA promoters ( $\mathrm{Cp}, \mathrm{Wp}$ and $\mathrm{Op}$ ). In this study, we examined the EBNA promoter usage by RT-PCR and the methylation status in the $\mathrm{Cp}$ and $\mathrm{Wp}$ regions using bisulfite $\mathrm{PCR}$ analysis in spleen samples from CAEBV patients. EBNA1 transcripts were unexpectedly initiated not from Op but from Cp in all samples in spite of the restricted form of latency. Furthermore, while Cp was active, Cp was heavily methylated, indicating that CAEBV has unique EBV latent gene expression, EBNA promoter usage and EBNA promoter methylation status, in part due to unique splicing of $\mathrm{Cp}$-initiated transcripts and an activation mechanism in hypermethylated $\mathrm{Cp}$.
\end{abstract}

\section{INTRODUCTION}

Epstein-Barr virus (EBV) is a human herpesvirus that persists for the lifetime of the infected host and is associated with an array of conditions that range from asymptomatic infection and infectious mononucleosis (IM) to lethal lymphoid and epithelial malignancies, such as lymphoproliferative disease (LPD), nasopharyngeal carcinoma (NPC), Burkitt's lymphoma (BL), Hodgkin's disease (HD) and B-cell lymphoma in the immunocompromised host (Griffin, 2000). EBV has been recognized as a B-lymphotropic virus. However, recent evidence indicates that EBV can also infect T cells (Jones et al., 1988; Kikuta et al., 1988). EBV may play a role in the development of non-neoplastic T-cell LPD, including chronic active EBV infection (CAEBV) (Kikuta et al., 1988, 1989; Ohga et al., 1999) and EBVassociated haemophagocytic syndrome (EBV-AHS) (Kawaguchi et al., 1993; Su et al., 1994). CAEBV is characterized by IM-like symptoms, such as fever, lymphadenopathy, splenomegaly and hepatitis, which persist over a period of months to several years. Laboratory findings include anaemia, thrombocytopenia, leukopenia and hypergammaglobulinaemia with extremely high titres of antibodies against EBV lytic-cycle proteins (Rickinson, 1986; Schooley et al., 1986). In EBV-positive neoplastic T-cell lymphoma, viral transcripts consisting of EBV nuclear antigen 1 (EBNA1), latent membrane protein 1 (LMP1) and LMP2A/2B have been detected by RT-PCR (Chen et al., 1993). This expression pattern is characteristic of latency II EBV infection. We previously reported that EBNA1 transcripts were consistently detected in all samples from five CAEBV patients but that EBNA2 transcripts were detected in only one spleen sample (Yoshioka et al., 2001). These results indicated that the restricted form of EBV latency might play a pathogenic role in the development of CAEBV. However, the exact nature of CAEBV, neoplastic or non-neoplastic LPD, is still not known.

It has been reported that several mechanisms, including methylation and action of viral latent proteins and cellular factors, operate to regulate the promoters and control latent gene expression. Methylation of the cytosine residue of $\mathrm{CpG}$ dinucleotides $(\mathrm{CpG})$ in eukaryote DNA is an important mechanism of promoter regulation and genetic imprinting (Singal \& Ginder, 1999). EBV latent gene expression is controlled by distinct usage of three promoters (Cp, Wp and Qp). Promoter activity has been shown to be inversely correlated with the methylation status of promoters, although Qp is a remarkable exception (Robertson et al., 1995, 1996; Robertson \& Ambinder, 1997a, b; Falk 
et al., 1998; Salamon et al., 2001; Tierney et al., 2000b). When $\mathrm{Cp}$ is hypomethylated, it permits expression of all EBNAs during latency III. On the other hand, Qp gives rise to a selective expression of EBNA1 during latency I, while latency II is characterized by expression of EBNA1, LMP1 and LMP2 with transcripts initiated from Qp and LMP promoters (Brooks et al., 1992; Deacon et al., 1993). Cp was hypermethylated and inactivated in BL and HD (Robertson et al., 1996; Tierney et al., 2000a). Multiple usage of Cp, Wp and Qp was found in EBV-infected cells of patients with IM (Tierney et al., 1994; Laytragoon-Lewin et al., 1997; Niedobitek et al., 1997). Wp was hypermethylated and Cp was completely unmethylated in most patients with IM (Tierney et al., 2000a). Promoter usage in healthy carriers is controversial (Tierney et al., 1994; Chen et al., 1995). Robertson et al. (1997b) reported that about half of Cp was methylated in healthy carriers. Paulson \& Speck (1999) reported that $\mathrm{Wp}$ was hypermethylated but that $\mathrm{Cp}$ was only sparsely to moderately methylated in healthy carriers. The purpose of this study was to determine the EBNA promoter usage and to characterize the methylation status of the $\mathrm{Cp}$ and $\mathrm{Wp}$ regions in CAEBV.

\section{METHODS}

Tissue samples and cells. Spleen samples were obtained from five patients with CAEBV after obtaining informed consent from the patients' parents. The diagnosis of CAEBV was based on clinical and virological evidence. The results of the serological study, cell types and clonality of EBV-infected cells are summarized in Table 1 . The AKATA cell line and B95-8 EBV-immortalized reference cell line (R-LCL) were used as positive controls for Qp-initiated transcripts and $\mathrm{Cp} / \mathrm{Wp}$-initiated transcripts by RT-PCR, respectively. The BJAB cell line was used as a negative control for all RT-PCR analyses.

Genomic DNA was extracted from frozen tissue samples by standard methods as previously reported (Yoshioka et al., 2001). Total RNA was extracted from frozen spleen samples and cell lines using an RNAzol B (TEL-TEST) according to the manufacturer's protocol.

RT-PCR. Five spleen samples were examined for the presence of viral RNA transcripts by RT-PCR. The conditions for RT-PCR were described previously (Yoshioka et al., 2001). The primer pairs were designed in order to characterize the promoter usage of EBNA1 transcripts (Fig. 1, Table 2). Cp- and Wp-initiated transcripts have BamHI-C1/C2/W1/W2- and BamHI-W0/W1/W2-spliced structures, respectively. Therefore, the primer pair $\mathrm{C} 1 / \mathrm{C} 2-5^{\prime}$ and $\mathrm{W} 2-3^{\prime}$ was used for Cp-initiated transcripts, and the primer pair W0/W1-5' and W2-3' was used for Wp-initiated transcripts. Since Qp-initiated transcripts have a BamHI-Q/U/K-spliced structure, the primer pair Q-5' and K-3' was used for the first amplification and the primer pair $\mathrm{U}-5^{\prime}$ and $\mathrm{K}-3^{\prime}$ was used for the second amplification for Qpinitiated transcripts. To evaluate the sensitivity of the RT-PCR, serial 10-fold dilutions of cDNA from the positive control for each RTPCR analysis were subjected to PCR.

Southern blot hybridization. Aliquots $(10 \mu \mathrm{l}$ each) of the PCRamplified product were subjected to electrophoresis through a $1.0 \%$ agarose gel and transferred onto Hybond ECL nitrocellulose membranes (Amersham Pharmacia). Hybridization and washing were then performed according to the manufacturer's protocol. The W1/ W2- and U/K-spliced PCR-amplified products from the R-LCL were cloned into the pCR2.1-TA cloning vector (Invitrogen), and the cloned fragments were labelled by ECL random prime labelling and detection systems (Amersham Pharmacia) and used as probes for $\mathrm{Cp} / \mathrm{Wp}-$ and Qp-initiated transcripts, respectively. The W1/W2spliced products were amplified by the PCR using the primer pair W1-5' (5'-GAGACCGAAGTGAAGGCCCT-3') coordinates 1456114580 ) and $\mathrm{W} 2-3^{\prime}$. Similarly, PCR-amplified products of $\beta$-actin were used as a probe for $\beta$-actin.

Bisulfite PCR analysis of EBV genome methylation. Before bisulfite PCR analysis, untreated DNA was sequenced to confirm the sequences of the CpG sites in the samples. Although several point mutations were detected in promoter regions, the primers used in this study were not affected by the mutations (data not shown). The methylation status of $\mathrm{CpG}$ was determined by methylation-specific bisulfite PCR analysis (Frommer et al., 1992; Herman et al., 1996; Kubota et al., 1997) in five spleen samples. In this method, the bisulfite treatment converts unmethylated cytosine to uracil but does not affect the methylated cytosine. PCR primers that anneal selectively to unmethylated DNA after bisulfite conversion were designed. Briefly, $10 \mu \mathrm{g}$ aliquots of DNA were denatured in $\mathrm{NaOH}\left(0 \cdot 2 \mathrm{~mol} \mathrm{l}^{-1}\right)$ for $10 \mathrm{~min}$ at $37^{\circ} \mathrm{C}$. Each sample was resuspended in $520 \mu \mathrm{l}$ of freshly prepared sodium bisulfite $\left(3.0 \mathrm{~mol} \mathrm{l} \mathrm{l}^{-1}\right.$; Sigma) and $30 \mu \mathrm{l}$ of hydroquinone (10 mmol $\mathrm{l}^{-1}, \mathrm{pH} \mathrm{5}$; Sigma), overlaid with mineral oil and incubated for $20 \mathrm{~h}$ at $50^{\circ} \mathrm{C}$. After incubation, the bisulfitemodified DNA was purified and desalted with a Wizard DNA Clean-up system (Promega), desulfonated in $\mathrm{NaOH}\left(0 \cdot 3 \mathrm{~mol} \mathrm{l}^{-1}\right)$,

Table 1. EBV virological study in patients with chronic active EBV infection

For reference see Yoshioka et al. (2001). Abbreviations: VCA, viral capsid antigen; EA, early antigen; EBNA, EBV nuclear antigen; ND, not determined.

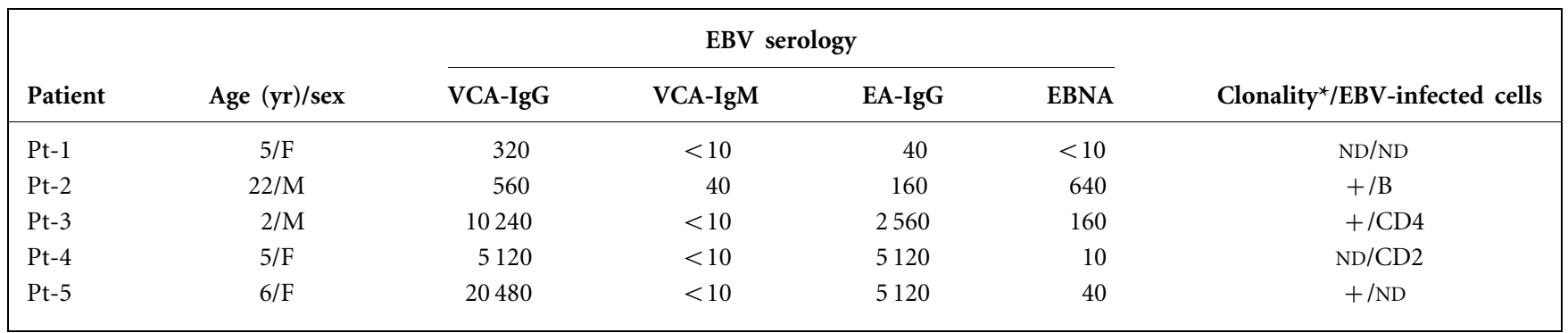

${ }^{\star}$ Clonality of EBV-infected cells was determined by terminal repeat analysis. 


\section{Cp-initiated mRNA}

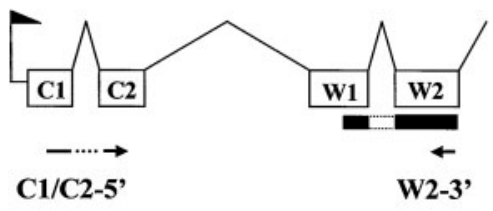

Wp-initiated mRNA
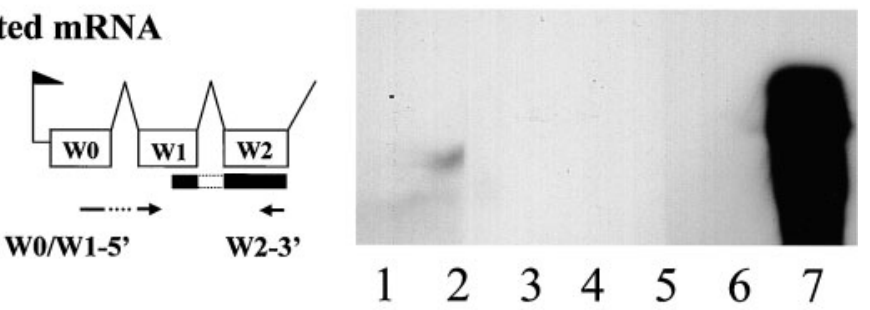

\section{Qp-initiated mRNA}

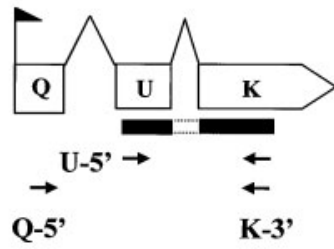

\section{$\beta$-actin mRNA}

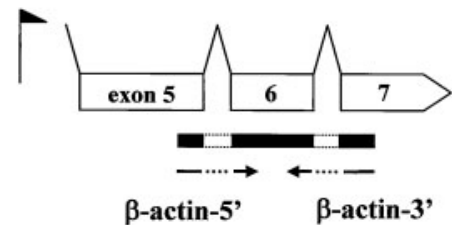

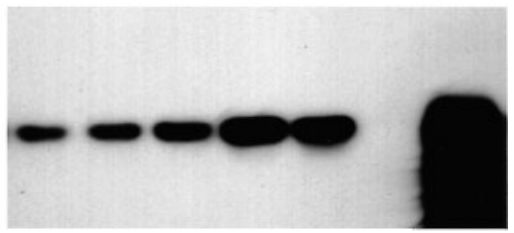
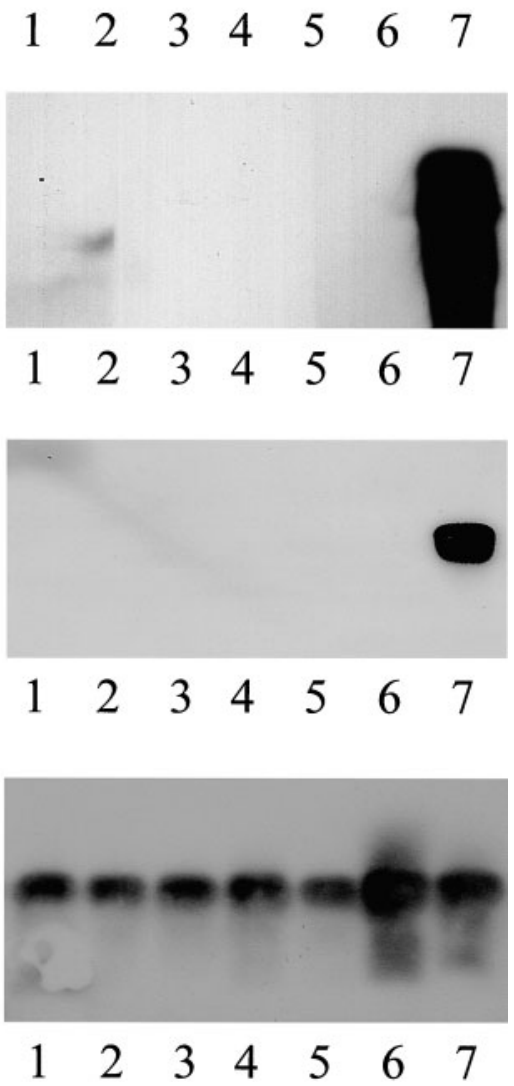

Fig. 1. RT-PCR analysis of EBNA promoter usage in patients with chronic active EBV infection. Results of Southern blot hybridization are shown together with the exons (boxes), primers (arrows), probe sites (closed box) and sites of transcriptional promoter (flags) for each mRNA. Lane $1, \mathrm{pt}-1$; lane 2, pt-2; lane 3, pt-3; lane 4, pt-4; lane 5 , pt-5; lane 6 , negative control; lane 7 , positive control.

Table 2. Primer sequences used for RT-PCR analysis

\begin{tabular}{|c|c|c|c|c|}
\hline Promoter usage & Primer & Sequence $\left(5^{\prime}-3^{\prime}\right)$ & Coordinates $^{*}$ & Reference \\
\hline $\mathrm{Cp}$ & $\mathrm{C} 1 / \mathrm{C} 2-5^{\prime}$ & CATCTAAACCGACTGAAGAA & $11470-11479 / 11626-11635$ & Tierney et al. (1994) \\
\hline Wp & W0/W1-5' & GTCCACACAAATCCTAG & $14399-14410 / 14554-14558$ & Tierney et al. (1994) \\
\hline $\mathrm{Cp}$ and $\mathrm{Wp}$ & Q-5' & GTGCGCTACCGGATGGCG & $62440-62457$ & Tierney et al. (1994) \\
\hline \multirow[t]{2}{*}{ Qp } & $\mathrm{U}-5^{\prime}$ & GATGAGCGTTTGGGAGAGCTGATTCTGCA & $67510-67539$ & Imai et al. (1996) \\
\hline & $\beta$-actin-3' & CCTCGTTACTAGAACTAGAAG & & Busson et al. (1992) \\
\hline
\end{tabular}

${ }^{*}$ The coordinates are given with reference to the B95-8 genomic sequence (Baer et al., 1984).

precipitated with ammonium acetate (Wako), ethanol and $1.2 \mu \mathrm{g}$ of carrier glycogen (Boehringer Mannheim), and resuspended in $50 \mu \mathrm{l}$ of sterile deionized water. For each sample, $2 \mu \mathrm{l}$ aliquots of bisulfite-modified DNA were amplified with primers specific for the regulatory regions of $\mathrm{Cp}$ and $\mathrm{Wp}$ as shown in Table 3.

The PCR-amplified products were then cloned into the pCR2.1-TA cloning vector. Four to 10 colonies were analysed for each DNA sample. Each clone analysed was generated from an independent bisulfite PCR reaction and therefore reflects amplification of independent viral genomes. Plasmid DNA was extracted and sequenced using a BigDye Dye terminator cycle sequencing ready reaction kit (Perkin Elmer Applied Biosystems) with an ABI PRISM 310 Genetic Analyser (Perkin Elmer Applied Biosystems). 
Table 3. Primer sequences used for bisulfite PCR analysis

\begin{tabular}{|lcc|}
\hline Primer $^{*}$ & Sequence $\left(\mathbf{5}^{\prime} \mathbf{-} \mathbf{3}^{\prime}\right)$ & Coordinates $\dagger$ \\
\hline $\mathrm{Cp}-5^{\prime}$ outer & ATATCCCAATTAAAAACCC & $10843-10861$ \\
$\mathrm{Cp}-3^{\prime}$ outer & GTTAAGTGGGTTTATATGGT & $11425-11406$ \\
$\mathrm{Cp}-5^{\prime}$ inner & CATACACCCTAAACCAACC & $10898-10916$ \\
$\mathrm{Cp}-3^{\prime}$ inner & ATGAGGGTTTTGGGGGTTT & $11385-11367$ \\
Wp-5' outer & CCCCCAAACTTTATCCAAATA & $13796-13816$ \\
Wp-3' outer & TGGAGTGTTGGGTTTAGTAG & $14660-14641$ \\
Wp-5' inner & CCTATCACCAAACCTACCA & $13918-13936$ \\
Wp-3' inner & GGGGAAAAGTTAGAAATTGGGT & $14486-14469$ \\
\hline
\end{tabular}

${ }^{\star}$ Primer sequences obtained from Paulson et al. (1999).

$\dagger$ The coordinates are given with reference to the B95-8 genomic sequence (Baer et al., 1984).

\section{RESULTS}

\section{RT-PCR}

U/K-spliced EBNA1 transcripts were consistently detected in all samples from the five CAEBV patients as described previously (Yoshioka et al., 2001). In this study, C1/C2/W2initiated transcripts were detected in all samples, but none of the samples expressed Wp- or Qp-initiated transcripts (Fig. 1). These results showed that EBNA1 transcription was initiated from $\mathrm{Cp}$ in all samples. Cp-, Wp- and Qp-initiated transcripts could be detected down to dilutions of $10^{-5}$, $10^{-4}$ and $10^{-4}$ of cDNA from the positive controls, respectively. EBNA gene transcripts, promoter usage and sensitivities are summarized in Table 4.

\section{Bisulfite analysis of EBV genome methylation}

Fig. 2 shows the methylation status of the regulatory regions upstream of the EBNA gene promoters, $\mathrm{Cp}$ and $\mathrm{Wp}$, in samples from the five CAEBV patients.
Cp (Fig. 2A). A total of 35 clones in samples from the five CAEBV patients were sequenced, and the methylation status at $21 \mathrm{CpG}$ sites in the $\mathrm{Cp}$ region was analysed. Of a total of 735 sites examined, 649 (88\%) were methylated. Two cellular factors, CBF2 and RBP-Jk/CBF1, can activate $\mathrm{Cp}$ by binding to the EBNA2 response region in the $\mathrm{Cp}$ region. Binding of $\mathrm{CBF} 2$ to the site is inhibited by CpG methylation, but binding of CBF1 is not inhibited (Robertson et al., 1995, 1996). Therefore, methylation of the EBNA2 response region of $\mathrm{Cp}$ abolishes binding of $\mathrm{CBF} 2$ and silences the promoter. $\mathrm{CpG}$ cytosines at nucleotide positions 10985 and 10988, the critical CpG sites affecting CBF2 binding, were methylated at $84 \%$ of the sites. These results indicated that $\mathrm{Cp}$ might be inactive in CAEBV samples.

Wp (Fig. 2B). A total of 26 clones in samples from the five CAEBV patients was sequenced, and the methylation status at $18 \mathrm{CpG}$ sites in the $\mathrm{Wp}$ region was analysed. Of a total of 468 sites analysed, $378(81 \%)$ were methylated. The transcription factors, such as YY1, BSAP/Pax5, RFX family protein and CREB family protein, are important for Wp activation in B cells (Bell et al., 1998; Kirby et al., 2000; Tierney et al., 2000a, b). CpG cytosines at nucleotide positions 14085, 14101, 14143, 14259, 14261, 14288, 14290 and 14296, which are present around the binding sites of these transcription factors, were almost completely methylated in CAEBV. These results indicated that the activation of Wp by these factors might be inhibited.

\section{DISCUSSION}

Expression of different panels of latent gene products is controlled by use of three different EBNA promoters (Cp, $\mathrm{Wp}$ and $\mathrm{Qp})$. Cp and $\mathrm{Wp}$ permit the full spectrum of latent gene expression, as has been shown in IM or EBVimmortalized lymphoblastoid cell lines (LCLs) in vitro (Tierney et al., 1994; Kieff, 1996). In contrast, Qp usage has

Table 4. Summary of EBV transcripts in chronic active EBV infection and sensitivities of RT-PCR

Abbreviations: PC, positive control; NC, negative control; R-LCL, B95-8 EBV-immortalized reference cell line; EBNA, EBV nuclear antigen; NT, not tested.

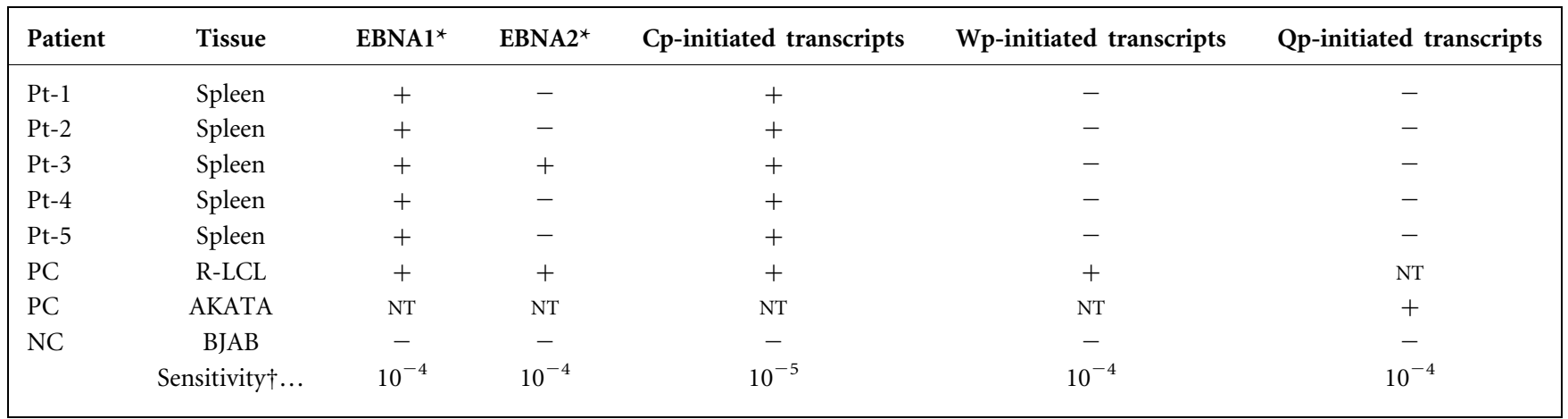

*Transcripts and sensitivities of EBV latent genes were reported by Yoshioka et al. (2001).

$\dagger$ Maximum dilution of cDNA in which a positive signal could be detected in each RT-PCR. 
(A)

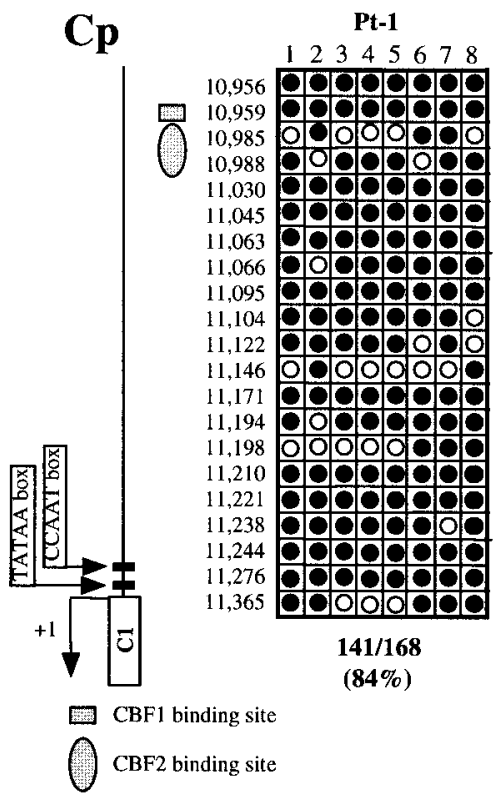

Pt-2

123345

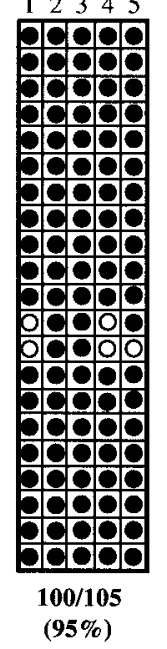

Pt-3

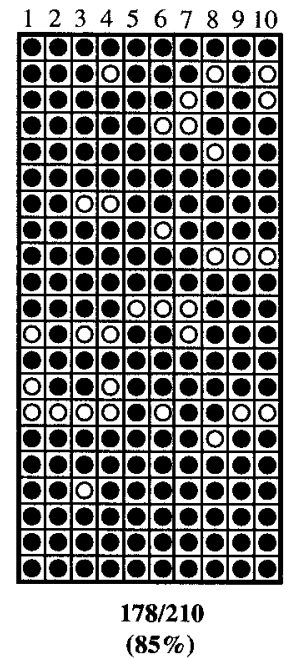

Pt-4

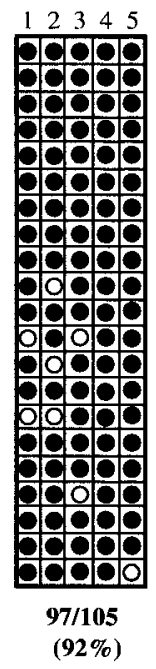

Pt-5

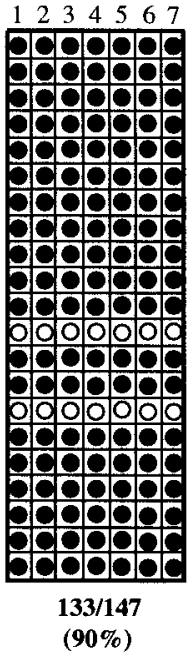

$649 / 735=88 \%$

(B)

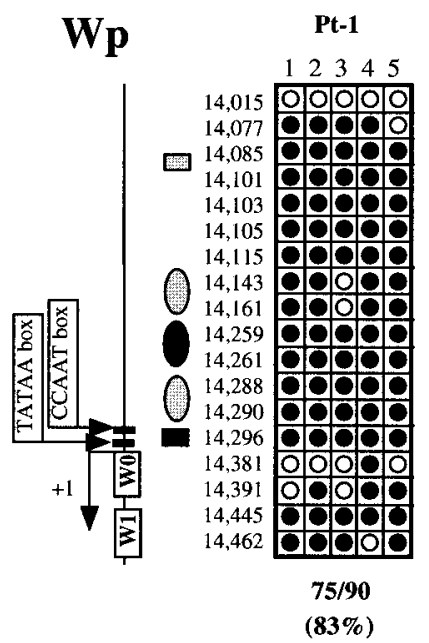

Pt-2

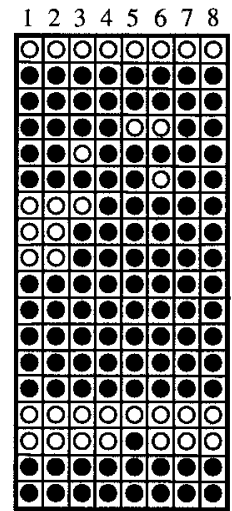

$110 / 144$

$(76 \%)$
Pt-3

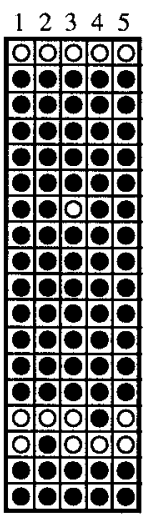

76/90

(84\%)
Pt-4

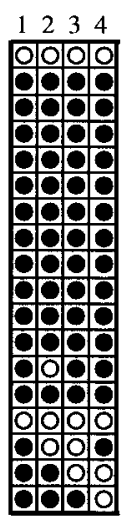

$\mathbf{5 8 / 7 2}$

$(\mathbf{8 1 \% )}$
Pt-5

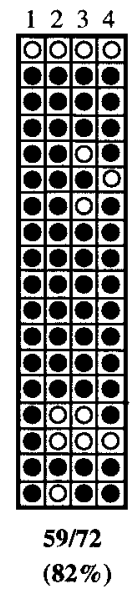

YYin binding site
BSAP binding site

$378 / 468=81 \%$

Fig. 2. Methylation status of the EBNA1 gene promoters, $\mathrm{Cp}$ and $\mathrm{Wp}$, in patients with chronic active EBV infection. The genome coordinate for each CpG site is given with reference to the B95-8 genomic sequence (Baer et al., 1984). -, methylated CpG; $\bigcirc$, unmethylated CpG. (A) CpG methylation in the region upstream of Cp. The locations of the CCAAT box, the TATAA box, transcription start site and the $\mathrm{C} 1$ exon are shown. The transcription factors (CBF1 and CBF2) of Cp and the relative positions of the $\mathrm{CpG}$ site are also indicated. (B) $\mathrm{CpG}$ methylation in the region upstream of Wp. The locations of the CCAAT box, the TATAA box, transcription start site, the W0 exon and the W1 exon are shown. The transcription factors (YY1, BSAP, CREB, RFX) of Wp and the relative positions of the CpG site are also indicated. 
been reported in EBV-positive malignancies, such as BL, NPC and HD, which show restricted forms of latent gene expression (Brooks et al., 1992; Tao et al., 1998). We previously reported that EBV latent gene expression was restricted in CAEBV, indicating that $\mathrm{Qp}$, but not $\mathrm{Cp} / \mathrm{Wp}$, might be used in most cases of CAEBV (Yoshioka et al., 2001). However, Cp-initiated transcripts exclusively were detected in all samples, but none of the samples expressed Wp- or Qp-initiated transcripts. An EBV-positive T-cell lymphoma is a clonal expansion of a single EBV-infected cell with a pattern of gene expression of latency II, which may indicate Qp usage (Pallesen et al., 1993; Chiang et al., 1996). Cp usage in CAEBV was apparently distinct from promoter usage of neoplastic T-cell lymphoma. We examined the sensitivity of each RT-PCR analysis in order to determine whether the RT-PCR technique is sensitive enough for definitive analysis of EBNA promoter usage. $\mathrm{Cp}-, \mathrm{Wp}$ - and Qp-initiated transcripts could be detected down to a dilution of at least $10^{-4}$ of cDNA from the positive controls, as shown in Table 3. This indicated that the RT-PCR assay could detect Qp-initiated transcripts, if any are present. Furthermore, genomic DNA around the primer regions used was sequenced in the samples. Although several point mutations were detected around the primer regions, there were no mutations that would influence the annealing of PCR in the primer regions (data not shown). Moreover, PCR analysis was performed using another primer pair, reported by Zetterberg et al. (1999) to detect Q/U/K-spliced EBNA1 transcripts, but no Qp-initiated transcripts were detected (data not shown).

During latent EBV infection of human B lymphocytes, six EBNAs (EBNA1, EBNA2, 3A, 3B, 3C and LP) are expressed from a single complex transcriptional unit that spans nearly $100 \mathrm{~kb}$ of the viral genome by means of alternative splicing and alternative polyadenylation sites (Kieff, 1996). The first EBNA genes expressed are EBNA-LP and EBNA2, by initiation from Wp. Subsequently, transcription of EBNA2 activates Cp, LMP and a number of cellular promoters for growth response genes, and dominant promoter usage switches from Wp to Cp (Alfieri et al., 1991; Tierney et al., 2000a). Generally Cp-initiated EBNA1 cDNA has a $\mathrm{Y} 1 / \mathrm{Y} 2 / \mathrm{Y} 3 / \mathrm{U} / \mathrm{K}$-spliced structure downstream of W1/ W2 repeats. However, Tierney et al. (1994) reported that $\mathrm{C} 1 / \mathrm{C} 2 / \mathrm{W} 2$-initiated transcripts were detected in all 14 IM patient blood samples, whereas $\mathrm{Cp}$-initiated, $\mathrm{Y} 3 / \mathrm{U} /$ $\mathrm{K}$-spliced EBNA1 transcripts were detected in only half of the samples. We detected C1/C2/W2-initiated transcripts in all five samples but could not detect $\mathrm{Y} 3 / \mathrm{U} / \mathrm{K}$-spliced EBNA1 transcripts in any samples except for that from patient 4 (data not shown). Furthermore, several unique Cp-initiated transcripts that skipped one or more exons downstream of a Cp-initiated site have been reported (Bodescot \& Perricaudet, 1986; Qu \& Rowe, 1992, 1995). The mechanisms regulating alternative splicing and polyadenylation site usage within the EBNA transcription unit remain largely unknown. Although $\mathrm{Cp}$ permits the full spectrum of EBNA gene expression, EBV latent gene expression is restricted in CAEBV. Therefore, we speculate that $\mathrm{Cp}$-initiated transcripts have unique splicing patterns and preferentially induce EBNA1 transcripts in most cases of CAEBV.

Methylation of $\mathrm{CpG}$ is an important mechanism of promoter regulation and EBV latent gene expression. EBNA promoter activity has been shown to be inversely correlated with the methylation status of the promoters $\mathrm{Cp}$ (Robertson et al., 1995, 1996; Robertson \& Ambinder, 1997a, b; Salamon et al., 2001), Wp (Tierney et al., 2000b) and LMP1 (Falk et al., 1998). Methylation may inhibit transcription by a number of mechanisms, either by direct blocking of the binding of transcription factors to DNA or through mediation of methyl-CpG-binding proteins, which recruit histone deacetylases to the DNA, leading to the remodelling of chromatin into an inactive configuration (Singal \& Ginder, 1999). Wp is exclusively utilized during the initial stage of EBV infection in primary B lymphocytes, followed by a switch to Cp usage (Alfieri et al., 1991; Tierney et al., 2000a). Hypermethylation in the Wp region indicated that the promoter of EBNA might have already switched from $\mathrm{Wp}$ to $\mathrm{Cp}$ or Qp in CAEBV, which is consistent with the results of transcriptional analysis. The mechanism of $\mathrm{Wp}$ down-regulation in CAEBV might be the same as that in EBV-infected B cells, and hypermethylation of Wp might be sufficient to prevent transcription from $\mathrm{Wp}$ in CAEBV. $\mathrm{Qp}$ is a TATA-less promoter at the centre of a hypomethylated island (Schaefer et al., 1995). Qp was found to be completely unmethylated in samples from patients (data not shown). Qp might be inactivated by several factors, such as EBNA1, E2F, interferon response factors (IRFs)-1, -2 and -7 and high-mobility group protein (HMG)-I (Y)containing complex, under the conditions of $\mathrm{Cp}$ activation in CAEBV (Sung et al., 1994; Schaefer et al., 1997; Chen et al., 1999).

Cp activity is the major difference between latency III and the other latency forms. Several mechanisms that may regulate $\mathrm{Cp}$ activity have been described. First, $\mathrm{Cp}$ can be activated by binding of EBNA1 to oriP, an enhancer $3 \mathrm{~kb}$ upstream of Cp (Puglielli et al., 1996). Second, glucocorticoid response elements (GREs) about $900 \mathrm{bp}$ upstream of $\mathrm{Cp}$ respond to glucocorticoids and activate $\mathrm{Cp}$ (Evans et al., 1996). Third, the EBNA2 response region in the Cp region is critical for $\mathrm{Cp}$ activity. The EBNA2 response region contains the binding sites for the cellular DNAbinding proteins $\mathrm{CBF} 1$ and $\mathrm{CBF} 2$. The methylation of CpG sequences in the CBF2-binding domain inhibits $\mathrm{Cp}$ activity, and CBF2 binding is crucial for EBNA2-mediated activation of Cp (Robertson et al., 1995, 1996). Finally, several cellular factors that control the transcription activity of $\mathrm{Cp}$ have been identified. NF-Y transcription factor interacts with the CCAAT box in the -71 to -63 region of Cp. Members of the C/EBP transcription factor family interact with the C/EBP consensus sequence in the -119 to -112 region of $\mathrm{Cp}$. Sp1 and Egr-1 interact with a GCrich sequence in the -99 to -91 region of Cp. NF-Y, 
members of the C/EBP, and Sp1 are positive regulators of $\mathrm{Cp}$ activity, and Egr-1 is a negative regulator of $\mathrm{Cp}$ activity (Nilsson et al., 2001).

There was a discrepancy between $\mathrm{Cp}$ usage and the hypermethylation status of the Cp region in CAEBV. The level of methylation in the $\mathrm{Cp}$ region in CAEBV was, surprisingly, as high as that in BL (Robertson et al., 1996; Tierney et al., 2000a). We cannot rule out the possibility that we could not detect cells with unmethylated Cp by bisulfite PCR analysis because the population size of such cells was very small. However, since $\mathrm{Cp}$ is regulated in a very complex manner as mentioned above, it could be concluded that the hypermethylation status of the $\mathrm{Cp}$ region might be insufficient to prevent transcription from $\mathrm{Cp}$. This finding is consistent with the genetic analysis of Cp function by Evans et al. (1996). Furthermore, CAEBV is considered to be a T-cell LPD and only occasionally a B-cell LPD. Patient 2 was a rare case of B-cell LPD, but the methylation status was the same as that of T-cell LPD, indicating that hypermethylation in the $\mathrm{Cp}$ region occurs regardless of the phenotypic difference in EBV-infected cells.

In this study, we found unique EBV latent gene expression, EBNA promoter usage and methylation status of EBNA promoters in CAEBV. The unique relationships, seemingly contradictive, might offer the key for understanding the pathogenesis of CAEBV.

\section{ACKNOWLEDGEMENTS}

This research was supported by an Akiyama Foundation grant. The authors thank Mr Stewart Chisholm for proofreading the manuscript.

\section{REFERENCES}

Alfieri, C., Birkenbach, M. \& Kieff, E. (1991). Early events in EpsteinBarr virus infection of human B lymphocytes. Virology 181, 595-608.

Baer, R., Bankier, A. T., Biggin, M. D. \& 9 other authors (1984). DNA sequence and expression of the B95-8 Epstein-Barr virus genome. Nature 310, 207-211.

Bell, A., Skinner, J., Kirby, H. \& Rickinson, A. (1998). Characterisation of regulatory sequences at the Epstein-Barr virus BamHI W promoter. Virology 252, 149-161.

Bodescot, M. \& Perricaudet, M. (1986). Epstein-Barr virus mRNAs produced by alternative splicing. Nucleic Acids Res 14, 7103-7114.

Brooks, L., Yao, Q. Y., Rickinson, A. B. \& Young, L. S. (1992). Epstein-Barr virus latent gene transcription in nasopharyngeal carcinoma cells: coexpression of EBNA1, LMP1, and LMP2 transcripts. J Virol 66, 2689-2697.

Busson, P., McCoy, R., Sadler, R., Gilligan, K., Tursz, T. \& RaabTraub, N. (1992). Consistent transcription of the Epstein-Barr virus LMP2 gene in nasopharyngeal carcinoma. J Virol 66, 3257-3262.

Chen, C. L., Sadler, R. H., Walling, D. M., Su, A. I. J., Hsieh, H. C. \& Raab-Traub, N. (1993). Epstein-Barr virus (EBV) gene expression in EBV-positive peripheral T-cell lymphoma. J Virol 67, 6303-6308.

Chen, F., Zou, J. Z., di Renzo, L., Winberg, G., Hu, L. F., Klein, E., Klein, G. \& Ernberg, I. (1995). A subpopulation of normal B cells latently infected with Epstein-Barr virus resembles Burkitt lymphoma cells in expressing EBNA-1 but not EBNA-2 or LMP1. J Virol 69, 3752-3758.

Chen, H., Lee, J. M., Wang, Y., Huang, D. P., Ambinder, R. F. \& Hayward, S. D. (1999). The Epstein-Barr virus latency BamHI-Q promoter is positively regulated by STATs and Zta interference with JAK/STAT activation leads to loss of BamHI-Q promoter activity. Proc Natl Acad Sci U S A 96, 9339-9344.

Chiang, A. K., Tao, Q. \& Ho, F. C. (1996). Nasal NK- and T-cell lymphomas share the same type of Epstein-Barr virus latency as nasopharyngeal carcinoma and Hodgkin's disease. Int J Cancer 68, 285-290.

Deacon, E. M., Pallesen, G., Niedobitek, G., Crocker, J., Brooks, L., Rickinson, A. B. \& Young, L. S. (1993). Epstein-Barr virus and Hodgkin's disease: transcriptional analysis of virus latency in the malignant cells. J Exp Med 177, 339-349.

Evans, T. J., Farrell, P. J. \& Swaminathan, S. (1996). Molecular genetic analysis of Epstein-Barr virus Cp promoter function. J Virol 70, 1695-1705.

Falk, K. I., Szekely, L., Aleman, A. \& Ernberg, I. (1998). Specific methylation patterns in two control regions of Epstein-Barr virus latency: the LMP-1-coding upstream regulatory region and an origin of DNA replication (oriP). J Virol 72, 2969-2974.

Frommer, M., Mcdonald, L. E., Millar, D. S., Collis, C. M., Watt, F., Grigg, G. W., Molloy, P. L. \& Paul, C. L. (1992). A genomic sequencing protocol that yields a positive display of 5-methylcytosine residues in individual DNA strands. Proc Natl Acad Sci U S A 89, $1827-1831$.

Griffin, B. E. (2000). Epstein-Barr virus (EBV) and human disease: facts, opinions and problems. Mutat Res 462, 395-405.

Herman, J. G., Graff, J. R., Myohanen, S., Nelkin, B. D. \& Baylin, S. B. (1996). Methylation-specific PCR: a novel PCR assay for methylation status of CpG islands. Proc Natl Acad Sci U S A 93, 9821-9826.

Imai, S., Sugiura, M., Oikawa, O. \& 9 other authors (1996). EpsteinBarr virus (EBV)-carrying and -expressing T-cell lines established from severe chronic active EBV infection. Blood 87, 1446-1457.

Jones, J. F., Shurin, S., Abramowsky, C. \& 7 other authors (1988). T-cell lymphomas containing Epstein-Barr viral DNA in patients with chronic Epstein-Barr virus infections. N Engl J Med 318, 733-741.

Kawaguchi, H., Miyashita, T., Herbst, H. \& 8 other authors (1993). Epstein-Barr virus-infected $\mathrm{T}$ lymphocytes in Epstein-Barr virusassociated hemophagocytic syndrome. J Clin Investig 92, 1444-1450.

Kieff, E. (1996). Epstein-Barr virus and its replication. In Fields Virology, 3rd edn, pp. 2343-2396. Edited by B. N. Fields, D. M. Knipe \& P. M. Howley. Philadelphia: Lippincott-Raven.

Kikuta, H., Taguchi, Y., Tomizawa, K. \& 12 other authors (1988). Epstein-Barr virus genome-positive $\mathrm{T}$ lymphocytes in a boy with chronic active EBV infection associated with Kawasaki-like disease. Nature 333, 455-457.

Kikuta, H., Nakanishi, M., Sakiyama, Y. \& Matsumoto, S. (1989). Chronic active Epstein-Barr virus (EBV) infection is associated with clonotypic intracellular terminal regions of the EBV. J Infect Dis 160, 546-547.

Kirby, H., Rickinson, A. \& Bell, A. (2000). The activity of the EpsteinBarr virus BamHI W promoter in B cells is dependent on the binding of CREB/ATF factors. J Gen Virol 81, 1057-1066.

Kubota, T., Das, S., Christian, S. L., Baylin, S. B., Herman, J. G. \& Ledbetter, D. H. (1997). Methylation-specific PCR simplifies imprinting analysis. Nat Genet 16, 16-17.

Laytragoon-Lewin, N., Chen, F., Avila-Carino, J., Klein, G. \& Mellstedt, H. (1997). Epstein-Barr virus (EBV) gene expression in 
lymphoid B cells during acute infectious mononucleosis (IM) and clonality of the directly growing cell lines. Int J Cancer 71, 345-349.

Niedobitek, G., Agathanggekou, A., Herbst, H., Whitehead, L., Wright, D. H. \& Young, L. S. (1997). Epstein-Barr virus (EBV) infection in infectious mononucleosis: virus latency, replication and phenotype of EBV-infected cells. J Pathology 182, 151-159.

Nilsson, T., Zetterberg, H., Wang, Y. C. \& Rymo, L. (2001). Promoter-proximal regulatory elements involved in oriP-EBNA1independent and -dependent activation of the Epstein-Barr virus $\mathrm{C}$ promoter in B-lymphoid cell lines. J Virol 75, 5796-5811.

Ohga, S., Kimura, N., Takada, H. \& 7 other authors (1999). Restricted diversification of T-cells in chronic active Epstein-Barr virus infection: potential inclination to T-lymphoproliferative disease. Am J Hemat 61, 26-33.

Pallesen, G., Hamilton-Dutoit, S. J. \& Zhou, X. (1993). The association of Epstein-Barr virus (EBV) with T cell lymphoproliferations and Hodgkin's disease: two new developments in the EBV field. Cancer Res 62, 179-239.

Paulson, E. J. \& Speck, S. H. (1999). Differential methylation of Epstein-Barr virus latency promoters facilitates viral persistence in healthy seropositive individuals. J Virol 73, 9959-9968.

Puglielli, M. T., Woisetschlaeger, M. \& Speck, S. H. (1996). oriP is essential for EBNA gene promoter activity in Epstein-Barr virusimmortalized lymphoblastoid cell lines. J Virol 70, 5758-5768.

Qu, L. \& Rowe, D. T. (1992). Epstein-Barr virus latent gene expression in uncultured peripheral blood lymphocytes. J Virol 66, $3715-3724$.

Qu, L. \& Rowe, D. T. (1995). Epstein-Barr virus latent messages with shuffled leader exons: remnants of circumgenomic transcription? J Virol 69, 1050-1058.

Rickinson, A. B. (1986). Chronic, symptomatic Epstein-Barr virus infections. Immunol Today 7, 13-14.

Robertson, K. D. \& Ambinder, R. F. (1997a). Mapping promoter regions that are hypersensitive to methylation-mediated inhibition of transcription: application of the methylation cassette assay to the Epstein-Barr virus major latency promoter. J Virol 71, 6445-6454.

Robertson, K. D. \& Ambinder, R. F. (1997b). Methylation of the Epstein-Barr virus genome in normal lymphocytes. Blood 90, 44804484.

Robertson, K. D., Hayward, S. D., Ling, P. D., Samid, D. \& Ambinder, R. F. (1995). Transcriptional activation of the Epstein-Barr virus latency $\mathrm{C}$ promoter after 5-azacytidine treatment: evidence that demethylation at a single CpG site is crucial. Mol Cell Biol 15, 61506159.

Robertson, K. D., Manns, A., Swinnen, L. J., Zong, J. C., Gulley, M. L. \& Ambinder, R. F. (1996). CpG methylation of the major EpsteinBarr virus latency promoter in Burkitt's lymphoma and Hodgkin's lymphoma. Blood 88, 3129-3136.

Salamon, D., Takacs, M., Ujvari, D., Uhlig, J., Wolf, H., Minarovits, J. \& Niller, H. (2001). Protein-DNA binding and CpG methylation at nucleotide resolution of latency-associated promoter Qp, Cp, and LMP1p of Epstein-Barr virus. J Virol 75, 2584-2596.

Schaefer, B. C., Strominger, J. L. \& Speck, S. H. (1995). Redefining the Epstein-Barr virus-encoded nuclear antigen EBNA-1 gene promoter and transcription site in group I Burkitt lymphoma cell lines. Proc Natl Acad Sci U S A 92, 10565-10569.

Schaefer, B. C., Paulson, E., Strominger, J. L. \& Speck, S. H. (1997). Constitutive activation of Epstein-Barr virus (EBV) nuclear antigen 1 gene transcription by IRF1 and IRF2 during restricted EBV latency. Mol Cell Biol 17, 873-886.

Schooley, R. T., Carey, R. W., Miller, G., Henle, W., Eastman, R., Mark, E. J., Kenyon, K., Wheeler, E. O. \& Rubin, R. H. (1986). Chronic Epstein-Barr virus infection associated with fever and interstitial pneumonitis: clinical and serologic features and response to antiviral chemotherapy. Ann Intern Med 104, 636-643.

Singal, R. \& Ginder, G. D. (1999). DNA methylation. Blood 93, 4059-4070.

Su, I. J., Chen, R. L., Lin, D. T., Lin, K. S. \& Chen, C. C. (1994). Epstein-Barr virus (EBV) infects $\mathrm{T}$ lymphocytes in childhood EBVassociated hemophagocytic syndrome in Taiwan. Am J Pathol 144, 1219-1225.

Sung, N. S., Wilson, J., Davenport, M., Sista, N. D. \& Pagano, J. S. (1994). Reciprocal regulation of the Epstein-Barr virus BamHI-F promoter by EBNA-1 and E2F transcription factor. Mol Cell Biol 14, 7144-7152.

Tao, Q., Robertson, K. D., Manns, A., Hildesheim, A. \& Ambinder, R. F. (1998). The Epstein-Barr virus major latent promoter Qp is constitutively active, hypomethylated, and methylation sensitive. J Virol 72, 7075-7083.

Tierney, R. J., Steven, N., Young, L. S. \& Rickinson, A. B. (1994). Epstein-Barr virus latency in blood mononuclear cells: analysis of viral gene transcription during primary infection and in the carrier state. J Virol 68, 7374-7385.

Tierney, R. J., Kirby, H. E., Nagra, J. K., Desnond, J., Bell, A. I. \& Rickinson, A. B. (2000a). Methylation of transcription factor binding sites in the Epstein-Barr virus latent cycle promoter Wp coincides with promoter down-regulation during virus-induced B-cell transformation. J Virol 74, 10468-10479.

Tierney, R. J., Kirby, H. E., Nagra, J. K., Rickinson, A. B. \& Bell, A. (2000b). The Epstein-Barr virus promoter initiating B-cell transformation is activated by RFX proteins and the B-cell-specific activator protein BSAP/Pax5. J Virol 74, 10458-10467.

Yoshioka, M., Ishiguro, M., Ishiko, H., Ma, X., Kikuta, H. \& Kobayashi, K. (2001). Heterogeneous, restricted patterns of Epstein-Barr virus (EBV) latent gene expression in patients with chronic active EBV infection. J Gen Virol 82, 2385-2392.

Zetterberg, H., Stenglein, M., Jansson, A., Ricksten, A. \& Rymo, L. (1999). Relative levels of EBNA1 gene transcripts from the C/W, F and Q promoters in Epstein-Barr virus-transformed lymphoid cells in latent and lytic stages of infection. J Gen Virol 80, 457-465. 